\title{
Application Research of Artificial Intelligence Technology in Enterprise Financial Management
}

\author{
Jirong Dong \\ Zhixing College of Northwest Normal University, Gansu Lanzhou,730070
}

Keywords: artificial intelligence technology; enterprise financial management; application

\begin{abstract}
With the development of science and technology, artificial intelligence has gradually approached to our vision. In order to adapt to the development of society, enterprises have gradually introduced new technologies to make their management more modern. The financial department in the enterprise is the core of development. Therefore, some enterprises have introduced artificial intelligence technology in the finance department to improve the traditional financial work. Since artificial intelligence technology is an advanced technology in today's society and the world, the research and development of this technology are of great significance. This paper analyzes the concept of artificial intelligence technology, studies the characteristics of artificial intelligence technology in enterprise financial management, and explores the application of this technology in financial management.
\end{abstract}

With the development of society, science and technology are also constantly improving, and the research on artificial intelligence technology is gradually mature. Therefore, the development of all walks of life is gradually combined with artificial intelligence technology. In this context, artificial intelligence technology has brought new opportunities to the development of enterprises. In the financial management of enterprises, artificial intelligence technology can analyze big data, budget, planning, etc., and effectively improve the efficiency of financial management through the application of artificial intelligence technology.

\section{Artificial intelligence technology}

Artificial Intelligence, which is short for AI in English. It is a new technical science that studies and develops theories, methods, techniques, and applications that simulate, extend, and extend human intelligence. Artificial intelligence research scholars said that the advanced technology mainly uses computer programs to work, set the required data, problems, etc. in the program, and then solve the problem of data redundancy through system operation. The application of artificial intelligence technology in financial management is mainly embodied in office software. These software systems contain mathematical logic, control logic, computer science, information management and other subject knowledge. It can be seen that artificial intelligence technology is a Strong integrated technology ${ }^{[1]}$.

\section{The characteristics of artificial intelligence technology in enterprise financial management}

With the development of society, enterprises should achieve modern management if they continue to carry out internal reforms, so that they can keep up with the pace of development of the times and gain a foothold in the modernized market. The introduction of artificial intelligence technology is an inevitable choice for enterprise development. The main characteristics of artificial intelligence technology in enterprise financial management are management diversification, workflow, efficiency and value micro-level. The first is the management diversification. In the traditional financial management work, the work style is relatively simple, mainly because the financial staff repeat the same work every day, which is very boring and the work efficiency is relatively low. The application of artificial intelligence technology improves the financial work mode. The shortcomings, in the context of the use of artificial intelligence, companies can collect 
information through web pages, microblogging, video and many other aspects, financial management work has become more diverse. Secondly, it is the characteristics of workflow. In the traditional financial management work, there are manual calculation data and analysis data. The accounts in different periods are recorded in different books. When you need to query, you need to find and work according to the time limit. Without continuity, this mode of work is difficult to carry out systematic data analysis and budget, which is not conducive to better development of enterprises. After using artificial intelligence technology, the financial related data in the enterprise can be analyzed, entered and consulted at any time in a big data system. In the big data system, the artificial intelligence technology can accurately analyze the data information we need. Therefore, the process of financial work is more convenient and sequential. The third characteristic is efficiency and efficiency. In the traditional enterprise financial management work, the statistics of the data should be summed up after the project expenditure, and in the context of the application of artificial intelligence technology, the data can be analyzed, budgeted, etc. , statistics before the project expenditure, help companies save money and so on. The last feature is the value microprocessing. There will be a lot of data in the financial management work. When the manual calculation and analysis, some small data is easily neglected. The application of artificial intelligence technology can cover all the data information, making the financial management work more precise. Therefore, to a certain extent, it can be said that artificial intelligence technology is reflected in micro-value in the financial management of enterprises ${ }^{[2]}$.

\section{The impact of artificial intelligence technology on financial management}

With the maturity of artificial intelligence technology development, enterprises gradually combine traditional management methods with new technologies. The application of artificial intelligence technology in financial management has far-reaching significance. In the traditional financial management work, there are manual accounting and manual settlement. This management method has certain drawbacks, and it is prone to calculation errors or fraud, which affects the management and development of the financial department. The application of artificial intelligence technology in enterprise financial management standardizes the financial management work, so that the quality of financial management work has been effectively improved. The application of artificial intelligence technology can save the utilization of personnel in the financial management department of the enterprise. Big data can be analyzed by artificial intelligence. Therefore, in terms of human resource allocation, the finance department can reduce the labor cost, and at the same time, can ensure the financial work's accuracy. On the other hand, the application of artificial intelligence technology in financial management makes the workflow more standardized, and all relevant data of financial management can be managed in the system, so that the work can be carried out in an orderly manner ${ }^{[3]}$.

\section{The application of artificial intelligence technology in enterprise financial management}

\subsection{Application of management system}

Many companies are using ERP systems, which have general ledger, supply chain, cost management, production management, production planning and other modules in financial management. Financial staff can operate and organize financial information in the system to enable financial management of enterprises. Gradually realize the paperless and electronic mode. In the artificial intelligence management system, cost accounting and payable receivables can be automatically carried out, so artificial intelligence can replace the work of some employees and improve the efficiency of financial work.

\subsection{Electronic invoice and online reimbursement}

The finance department is in charge of the economic lifeline of the enterprise. The expenses incurred by the staff at work require the financial department to reimburse. In the traditional reimbursement, paper-based documents are required. These documents are not conducive to 
preservation. In artificial intelligence technology. In the application, enterprise staff can directly use the network platform and electronic invoices for reimbursement when reimbursing. For example, when an employee is on a business trip, he can use the APP to book a hotel in the software such as Meituan and Ctrip, and then save the electronic invoice on the network. Or the purchasing personnel in the enterprise can purchase the goods online at the time of purchase, and then upload the electronic bills and invoices to the artificial intelligence system of the enterprise finance. After the financial personnel accept it, they can be reimbursed after the review process, which makes the work more convenient.

\subsection{Financial accounting}

In the human resources allocation of the finance department, there are positions such as financial management personnel, cashiers, and auditors. In traditional financial work, all the documents, accounts, and records that need to be exchanged are required to be accounted for, and manual calculation and accounting are required. After there is no problem with the accounting records, it is handed over to the auditor to write off the documents. During the whole work process, a lot of staff are needed, and there are a lot of calculations, which are prone to errors. Artificial intelligence technology can play an important role in financial accounting. Robots instead of manual accounting and calculation in the program can effectively improve work efficiency and minimize errors. The artificial intelligence robot system has a huge calculation function. When there is a difference in the accounting process, the error analysis report can be given in time, so that the financial management personnel can understand the specific situation of the account.

\subsection{Analysis of financial data}

The development of an enterprise is inseparable from financial analysis, and the situation of financial management is also an intuitive manifestation of enterprise development. Manual financial analysis is not very rigorous, and the analysis includes less data. Unlike artificial intelligence technology, staff can enter relevant data in the enterprise into the artificial intelligence system, and then analyze according to the program. Artificial intelligence can analyze the business situation and profitability of the enterprise over the years, and according to the past the data analysis summarizes the direction of future development. In addition, artificial intelligence can also be analyzed according to different modules of enterprise development, such as the operation of production modules, the operation of marketing, the operation of human resources allocation, etc., which can fully make the situation of the enterprise the most scientific. The data form is displayed to help the development of the enterprise. To a certain extent, it can also enable enterprises to avoid risks and avoid losses in the development process.

\section{Summary}

In summary, according to the characteristics of artificial intelligence technology in enterprise financial management, it can be seen that the management mode combining financial management and artificial intelligence is an inevitable trend of enterprise development. While artificial intelligence technology improves the efficiency of corporate financial management, it also makes the management of enterprises more and more modern. Compared with financial management personnel, the current artificial intelligence technology is only an auxiliary tool for financial work and cannot replace the staff. Under such a social background, financial management personnel should also continuously improve their own quality and work ability so that they can better master the artificial intelligence technology to ensure the development with the company.

\section{References}

[1] Liang Rongrong. Application and Prospect of Artificial Intelligence in Enterprise Financial Management [J]. International Business Finance, 2018(6). 
[2] Wang Xiaolong. Application and Thinking of Business Intelligence (BI) in Financial Management [J]. Information and Computer (Theoretical Edition), 2017(16): 149-151.

[3] Yang Jing. Challenges and Coping Strategies Faced by Accounting Personnel in the Age of Financial Robotics [J]. China Market, 2018(1): 183-184. 